\title{
Risk taking behaviors in relation to Attention Deficit and Hyperactivity Disorder in Iranian male workers: a latent class analysis
}

This article was published in the following Dove Press journal:

Neuropsychiatric Disease and Treatment

\begin{abstract}
Abbas Abbasi-
Ghahramanloo'

Leila Janani ${ }^{2} *$

Seyed Kazem Malakouti ${ }^{3}$

Mahshid Rabetian ${ }^{3}$

Shahnaz Rimaz ${ }^{4, *}$

'Department of Epidemiology, School of Public Health, Iran University of Medical Sciences, Tehran, Iran; ${ }^{2}$ Preventive Medicine and Public Health Research Center, Department of Biostatistics, School of Public Health, Iran University of Medical Sciences, Tehran, Iran; ${ }^{3}$ Mental Health Research Center, Department of community psychiatry, Faculty of Behavioral Sciences and Mental health, Iran University of Medical Sciences, Tehran, Iran; ${ }^{4}$ Radiation Biology Research Center, Department of Epidemiology, School of Public Health, Iran University of Medical Sciences, Tehran, Iran

*These authors contributed equally to this work
\end{abstract}

Background: Risk taking behaviors are a serious risk to the health and safety of workers. The aims of this study were to identify the subgroups of workers on the basis of risk taking behaviors and assess the independent role of ADHD on the membership of participants in each latent class.

Methods: This cross sectional study was performed on 2434 workers. The sample was selected through random cluster sampling from Kaveh Industrial City. All workers completed five sets of checklists and questionnaires. Data analysis was performed using chi-square, Fisher's exact test, and latent class analysis.

Results: Four latent classes were identified; namely, 1) very low risk (65.6\%), 2) low risk $(27.8 \%)$, moderate risk $(4.1 \%)$ and, high risk $(2.5 \%)$. After adjusting for other studied covariates, having ADHD significantly increased the odds of membership in moderate risk class $(\mathrm{OR}=3.42,95 \% \mathrm{CI}: 2.21-5.29)$ and high risk class $(\mathrm{OR}=3.10,95 \% \mathrm{CI}: 1.80-5.34)$ compared to very low risk class. Also, having anxiety increased the odds of membership in latent class $2(\mathrm{OR}=1.28,95 \% \mathrm{CI}: 1.02-1.62), 3(\mathrm{OR}=2.15,95 \% \mathrm{CI}: 1.51-3.10)$ and 4 $(\mathrm{OR}=2.06,95 \% \mathrm{CI}: 1.32-3.22)$ in comparison to class 1. Among all participants, 187 (7.7\%) had ADHD and among studied variables, ADHD has the strongest role in the membership of subjects in different classes.

Conclusion: Results from the present study indicate that $6.6 \%$ of the workers fell under moderate or high risk class. Focusing on the treatment of ADHD with considering other comorbid factors such as anxiety may be helpful in designing and executing effective programs to reduce risk taking behaviors among workers.

Keywords: latent class analysis, risk taking behaviors, ADHD, workers

\section{Introduction}

Department of Epidemiology, School of Public Health, Iran University of Medical

Sciences, P.O Box: 14665-354 Shahid

Hemmat Highway, Tehran, Iran

Tel $+(98-21) 86709$

Fax $+(98-2 I) 88052248$

Email rimaz.sh@iums.ac.ir

Leila Janani

Department of Biostatistics, School of

Public Health, Iran University of Medical

Sciences, Shahid Hemmat Highway,

Tehran, Iran

Tel $+(98-21) 86709$

$\mathrm{Fax}+(98-2 \mathrm{I}) 88052248$

Email janani.l@iums.ac.ir
Risk taking behavior is defined as any behavior that can increase the risk of a specific disease, discomfort, and ill-health or directly impair the organs. These behaviors can lead not only negative and serious health related consequences but also socio-economic impacts as well. For example unintended pregnancies, sexually transmitted diseases, substance abuse, injuries, and even death. ${ }^{1-3}$

Several studies have pointed out the co-occurrence of risk taking behaviors among adults. For example, $59 \%$ of adults in Brazil, ${ }^{4} 68 \%$ in England, ${ }^{5}$ and $52 \%$ in the $\mathrm{US}^{6}$ were found to engage in two or more risk taking behaviors simultaneously.

Risk taking behaviors are a serious risk to the health and safety of workers. The workplace consequences of risk taking behaviors include injuries, poor work 
performance (includes missing work, arriving late/leaving early, doing less work, withdrawal behaviors and absenteeism) and problems such as fighting and insubordination. ${ }^{7,8}$ There is limited information about the prevalence and distribution of risk taking behaviors among workers in the world and specifically in Iran. For example, $3.1 \%$ of U.S workers reported illicit drug use before work or during working hours. ${ }^{9}$ Among street cleaner and manual workers of Zahedan city (Southeast of Iran), 7.8\% of them reported previous risk taking behaviors. ${ }^{1}$

A great deal of variable-centered research focused on the relationship between Attention Deficit and Hyperactivity Disorder (ADHD) and risk taking behaviors among different age groups. Individuals with ADHD are more likely to engage in risk taking behaviors and their negative outcomes. ${ }^{10}$ The relationship between ADHD and risk taking behaviors is more important among adults. ${ }^{11}$ About $30 \%$ of adults who are substance user have a concomitant ADHD and approximately 20 to $40 \%$ of adults with ADHD have histories of substance use disorders. ${ }^{12}$ ADHD can affect a lot of aspects of life. Some studies have reported a negative relationship between ADHD and self-esteem. ${ }^{13}$ On the other hand, anxiety is a common comorbid of $\mathrm{ADHD}^{14}$, with prevalence ranging from $15 \%$ to $35 \%$. ${ }^{15}$

Latent Class Analysis (LCA) is a person-centered approach that uses categorical and cross sectional observed indicators to find subtypes of related cases and yield latent classes of participants. ${ }^{16}$

Understanding of how risk taking behaviors co-occur is possible with subgrouping of workers based on these behaviors. Identifying these subgroups, as well as factors, predict co-occurrence of these behaviors is important for public health policymakers and health service providers. ${ }^{17,18}$

Based on above-mentioned background, the aims of this study were to identify the subgroups of workers based on risk taking behaviors and assess the independent role of ADHD on the membership of participants in each latent class after adjusting for other covariates.

\section{Materials and methods}

\section{Study population and sampling framework}

This cross sectional study was performed on 2434 workers from October 2017 to February 2019. The sample was selected through random cluster sampling from Kaveh Industrial City, a city in the center of Iran. All workers were eligible to participate in this study. Data were collected through the questionnaire and interview. Before interviews, some explanations were presented by the research team about the aims of the study, the anonymity of the questionnaires, and the voluntary nature of the participation in the study. The study was approved by the Ethics Committee of Iran University of Medical Sciences. Permission to conduct the study was obtained from this committee and all workers had signed an informed consent form.

All workers completed five sets of checklists and questionnaires. The first part assessed demographic information such as age, marital status and, etc. The second part evaluated information regarding various risk taking behaviors including general risk taking behaviors (lifetime), experiences of self-injury (lifetime), cigarette and hookah smoking (last year), alcohol consumption (last year), illicit drug use (lifetime) and sexual risk behaviors (last year). The questions about substance use had been prepared based on the World Health Organization (WHO) Core Questionnaires and WHO Alcohol, Smoking and Substance Involvement Screening Test (ASSIST) in previous studies in Iran by considering the situation of substance use in Iran. ${ }^{19,20}$ To assess whether or not the participants had sexual risk behavior in the last year, we used their response to the following question: "had you the extramarital heterosexual activity in the last year?" the next questions focus on the having unsafe sex. As a result, using illicit drugs or alcohol before the last sexual relationship or having sexual intercourse with numerous persons, or having sex without using a condom for prevention of sexually transmitted diseases was defined as sexual risk behaviors. $^{3}$

ADHD was measured using the Persian version of Conner's Adult ADHD Rating Scales 30-item questionnaire. The scale items were rated on a 0 -to-3 response scale as follow: "never (not at all), once in a while (just a little), often (pretty much) and very frequently (very much). This questionnaire was validated for adults ADHD in Iran. The scale has four subscales, comprising subscale A (inattention), subscale B (hyperactivity, impulsivity), subscale $\mathrm{C}(\mathrm{A}+\mathrm{B})$, and subscale $\mathrm{D}$ ( $\mathrm{ADHD}$ index). We used subscale $\mathrm{D}$ in this study. The overall score of this subscale varied from 0 to 36 and t a score of higher than 15 considered as "yes". 21

Additionally, the 10-item Rosenberg questionnaire was used to measure the self-esteem status of the workers. The scale 4-point items were rated on a $0-3$ response scale: "completely agree, agree, disagree, and completely disagree". 22 The 
overall score of this scale varied from 0 to 30 and a score of less than 15 considered as low self-esteem. ${ }^{23}$

Last part of the questionnaire assessed anxiety status among workers. This variable was measured using the Beck Anxiety Inventory (BAI) 21-item questionnaire. The scale items were rated on a 0-to-3 Not at allSeverely response scale as follow: "not at all, mildly, moderately and severely". The scores of this scale varied from 0 to 63 that scores higher than 21 considered as "yes". 24

\section{Statistical analysis}

The LCA model was used to detect the subgroups of risk taking behaviors among workers. According to this model, a number of observed (indicator) variables are aggregated to represent a categorical latent variable. In order to select the best fitted model, at first we calculated the $G^{2}$ index, which is an index similar to Chi-square. Also, the Akaike Information Criterion (AIC) and Bayesian Information Criterion (BIC) were calculated, for selection of the best model. For all of these indices, lower values indicate a better fit and parsimony for the model. We used item response probabilities of above 0.5 to label each latent class and describe its characteristics. Seven dichotomous observables (ie, indicators) were selected for subgrouping of workers. These indicators were general risk taking behaviors, the experience of self-injury, cigarette smoking, hookah smoking, alcohol use, illicit drug use, and sexual risk behaviors. After finalizing the model, we entered ADHD and other covariates in the LCA model. These covariates were age, marital status (married/single), education (academic/nonacademic), religiosity, anxiety (yes/no) and self-esteem (low/normal). Based on previous studies, the 2434 sample size was sufficient to run LCA. ${ }^{25,26}$

To perform simple statistical analysis, chi-square and Fisher's exact test were used with SPSS version 16. LCA were performed by using WinLTA (v. 3.1) and Stata version 10. In all analysis, $\mathrm{P}-$ value $<0.05$ was considered statistically significant.

\section{Results}

The present study showed that the mean age of the participants was $32.80 \pm 7.05$ (range: 18-67) years. Among all workers, $29.4 \%$ of them had academic education and only $1.6 \%$ was illiterate. The majority of the participants were married (72.2\%).

A summary of risk taking behaviors is shown in Table 1. The results suggested that some of the risk taking behaviors (e.g. hookah smoking) were more common than others. Also, the prevalence of experience of self-injury has the lowest prevalence among workers.

Table 1 also presents the conditional distribution of ADHD at each level of the risk taking behaviors. All items of risk taking behaviors have a significant relationship with ADHD.

We used seven binary variables to perform the LCA. We attempted to fit the LCA models with classes ranging from 1 to 8 . Different measures of model selection are shown in Table 2. As shown in this table, for each LCA model, $\mathrm{G}^{2}$, AIC, and BIC were computed. According to these model selection indices and interpretability of the results, we concluded that the four class model was appropriate for workers. Table 3 presents the result of the LCA model. As can see in this table, the first class, very low risk, described $65.6 \%$ of the workers. Also the second class, low risk, third class, moderate risk, and fourth class, high risk, described $27.8 \%, 4.1 \%$ and $2.5 \%$ of participants respectively.

Latent class 1 , very low risk, was characterized by low probability of risk taking behaviors and latent class 4 , high risk, was characterized by the high probability of all risk taking behaviors, except sexual risk behaviors. There were also two other latent classes reflected different patterns of risk taking behaviors. Latent class 2, low risk, was characterized by the high probability of hookah smoking. It should be noted that in this latent class, the probability of general risk taking behavior and cigarette smoking are relatively high. Latent class 3, moderate risk, was characterized by the high probability of general risk taking behaviors, cigarette smoking hookah smoking and, alcohol use.

Table 4 shows the odds ratio of membership in each class compared to first class, associated with ADHD and other covariates. This index compares the odds of membership in each class with the reference class (e.g. first class). As can be seen in Table 4, the odds of membership in classes 2 and 4 increased significantly by age. On the other hand, the odds off membership in class 3 significantly decreased by age. This table also shows that marital status significantly increased the odds of membership in class 2 and decreased this odds in class 3 and 4. Having academic education decreased the odds of membership in latent class 2 and 4 in comparison to class 1 .

In the case of religiosity, Table 4 indicates that a higher score of religiosity significantly decreased the odds of membership in class 3 and 4 compared to class 1. Also, having anxiety increased the odds of membership in latent 
Table I Risk taking behaviors by 'ADHD' in a sample of Iranian workers

\begin{tabular}{|c|c|c|c|c|}
\hline \multirow[t]{2}{*}{ Items } & \multirow{2}{*}{$\begin{array}{c}\text { Total } \\
\text { n (\%) }\end{array}$} & \multicolumn{2}{|l|}{ ADHD } & \multirow[t]{2}{*}{ P-value } \\
\hline & & $\begin{array}{l}\text { yes } \\
\text { n (\%) }\end{array}$ & $\begin{array}{l}\text { no } \\
\text { n (\%) }\end{array}$ & \\
\hline \multicolumn{5}{|c|}{ General risk taking behaviors (life time) } \\
\hline Yes & 505 & $75(40.3)$ & $428(19.3)$ & $<0.001$ \\
\hline No & $1912(78.6)$ & III (59.7) & $1787(80.7)$ & \\
\hline \multicolumn{5}{|c|}{ Experience of self- injury (life time) } \\
\hline Yes & $58(2.4)$ & $18(9.7)$ & $39(1.8)$ & $<0.001$ \\
\hline No & $2360(97.0)$ & $168(90.3)$ & $2177(98.2)$ & \\
\hline \multicolumn{5}{|c|}{ Cigarette smoking (last year) } \\
\hline Yes & $501(20.6)$ & $61(32.6)$ & $438(19.6)$ & $<0.001$ \\
\hline No & $1933(79.4)$ & $126(67.4)$ & $1793(80.4)$ & \\
\hline \multicolumn{5}{|c|}{ Hookah smoking (last year) } \\
\hline Yes & $626(25.7)$ & $93(49.7)$ & $528(23.7)$ & $<0.001$ \\
\hline No & $1808(74.3)$ & $94(50.3)$ & $1703(76.3)$ & \\
\hline \multicolumn{5}{|c|}{ Alcohol use (last year) } \\
\hline Yes & $244(10.0)$ & $50(26.7)$ & $190(8.5)$ & $<0.001$ \\
\hline No & $2190(90.0)$ & $137(73.3)$ & $204 \mid(91.5)$ & \\
\hline \multicolumn{5}{|c|}{ Illicit drug use (life time) } \\
\hline Yes & $147(6.0)$ & $32(17.1)$ & $114(5.1)$ & $<0.001$ \\
\hline No & $2287(94.0)$ & $155(82.9)$ & $2117(94.9)$ & \\
\hline \multicolumn{5}{|c|}{ Sexual risk behavior (last year) } \\
\hline Yes & $77(3.2)$ & $23(12.3)$ & $54(2.4)$ & $<0.001$ \\
\hline No & $2357(96.8)$ & $164(87.7)$ & $2177(97.6)$ & \\
\hline
\end{tabular}

Table 2 Comparison of LCA models with different latent classesbased on model selection statistics

\begin{tabular}{|l|l|l|l|l|l|l|l|}
\hline Number of latent class & Number of parameters estimated & $\mathbf{G}^{2}$ & df & AIC & BIC & Entropy & $\begin{array}{l}\text { Maximum } \\
\text { log-likelihood }\end{array}$ \\
\hline 1 & 7 & 1398.51 & 120 & $1412.5 I$ & 1453.09 & 1.00 & -5826.83 \\
2 & 15 & 184.40 & 112 & 214.40 & 301.36 & 0.76 & -5219.77 \\
3 & 23 & 118.69 & 104 & 164.69 & 298.03 & 0.67 & -5186.92 \\
4 & 31 & 90.82 & 96 & 152.82 & 332.54 & 0.73 & -5172.99 \\
5 & 39 & 71.50 & 88 & 149.50 & 375.59 & 0.71 & -5163.32 \\
6 & 47 & 60.88 & 80 & 154.88 & 427.35 & 0.74 & -5158.02 \\
7 & 55 & 52.92 & 72 & 162.92 & 481.77 & 0.75 & -5154.04 \\
8 & 63 & 46.97 & 64 & 172.97 & 538.20 & 0.78 & -5151.06 \\
\hline
\end{tabular}

Abbreviations: LCA, latent class analysis; AIC, Akaike information criterion; BIC, Bayesian information criterion.

class 2, 3 and 4 in comparison to class 1 . As can see in Table 4, having ADHD significantly increased the odds of membership in class 3(OR: 3.42, 95\% CI: $2.21-5.29)$ and class 4 (OR: $3.10,95 \% \mathrm{CI}: 1.80-5.34$ )compared to class 1. This table indicates that among the studied variables, ADHD had the strongest role in the membership of subjects in different classes. Also, only self-esteem didn't show a significant effect on the membership of workers in different classes.

\section{Discussion}

The results of this study indicated the prevalence of each risk taking behavior, namely general risk taking behaviors, the experience of self-injury, cigarette smoking, hookah 
Table 3 The four latent classes model of risk taking behaviors among Iranian workers

\begin{tabular}{|c|c|c|c|c|}
\hline & \multicolumn{4}{|l|}{ Latent class } \\
\hline & Very low risk & Low risk & Moderate risk & High risk \\
\hline Latent class prevalence & 0.656 & 0.278 & 0.041 & 0.025 \\
\hline \multicolumn{5}{|l|}{ Item-response probabilities } \\
\hline General risk taking behaviors & 0.090 & 0.378 & 0.592 & 0.810 \\
\hline Experience of self- injury & 0.004 & 0.017 & 0.022 & 0.638 \\
\hline Cigarette smoking & 0.071 & 0.400 & $0.7 I I$ & 0.736 \\
\hline Hookah smoking & 0.060 & 0.574 & 0.962 & 0.767 \\
\hline Alcohol use & 0.001 & 0.162 & 0.908 & 0.678 \\
\hline Illicit drug use & 0.000 & 0.145 & 0.121 & 0.596 \\
\hline Sexual risk behavior & 0.007 & 0.032 & 0.295 & $0.24 I$ \\
\hline
\end{tabular}

Notes: The probability of a "No" response can be calculated by subtracting the item-response probabilities shown above from I. *Item-response probabilities $>0.5$ in bold to facilitate interpretation.

Table 4 Predictors of membership in latent classes of risk taking behaviors among workers

\begin{tabular}{|c|c|c|c|c|c|}
\hline \multirow[t]{2}{*}{ Predictors } & Very low risk & Low risk & Moderate risk & High risk & \multirow[t]{2}{*}{ P-value } \\
\hline & OR(95\% Cl) & OR(95\% CI) & OR(95\% Cl) & OR(95\% Cl) & \\
\hline Age (year) & Reference & $1.06(1.04-1.07)$ & $0.94(0.90-0.97)$ & $1.07(1.04-1.11)$ & 0.019 \\
\hline Marital status (married/single) & Reference & $1.44(1.07-1.94)$ & $0.45(0.30-0.69)$ & $0.40(0.24-0.68)$ & 0.017 \\
\hline Education (academic/nonacademic) & Reference & $0.70(0.55-0.89)$ & $0.99(0.70-1.40)$ & $0.59(0.36-0.98)$ & 0.001 \\
\hline ADHD & Reference & $1.37(0.93-2.02)$ & $3.42(2.21-5.29)$ & $3.10(1.80-5.34)$ & $<0.001$ \\
\hline Religiosity & Reference & $0.97(0.92-1.01)$ & $0.80(0.75-0.84)$ & $0.71(0.67-0.75)$ & $<0.001$ \\
\hline Anxiety (yes/no) & Reference & $1.28(1.02-1.62)$ & $2.15(1.51-3.10)$ & $2.06(1.32-3.22)$ & 0.001 \\
\hline Self-esteem (low/normal) & Reference & $1.5 \mathrm{I}(\mathrm{I} .03-2.2 \mathrm{I})$ & $1.17(0.64-2.12)$ & $1.58(0.82-3.01)$ & 0.537 \\
\hline
\end{tabular}

smoking, alcohol use, illicit drug use and, sexual risk behavior. Hookah smoking was common behavior with a rate of prevalence of $25.7 \%$ and experience of self-injury was uncommon with a prevalence rate of $2.4 \%$. The literature review indicated that there are some national estimations for low stigma substances like cigarette and hookah in Iranian adults, however for high stigma ones like illicit drugs we couldn't find national reports. The pooled analysis of national surveys in 2006-2009 showed that the prevalence of hookah smoking ranged from 1.7 to $10.9 \%$ among Iranian adult men. ${ }^{27}$ The results of the present study represent that $20.6 \%$ of workers were a cigarette smoker. The results of four national surveys on Iranian adult population showed that the prevalence of current cigarette smoking was $25.6 \%$ in $2000,21.5 \%$ in $2005,24.9 \%$ in 2007 and $21.3 \%$ in 2011 among males. ${ }^{28}$ As a result, although the results aren't comparable it seems that the prevalence of hookah smoking among workers is higher than other adults, however, the prevalence of cigarette smoking is higher in adults.
In this study, we identified different patterns of risktaking risk taking behaviors with LCA and were able to detect four distinct classes that we named them as follows: very low risk, low risk, moderate risk, and high risk. The probability of engaging in each risk taking behavior is quite low among the workers in the latent class 1 . In the second class, however, the probability of hookah smoking is high. Also, the probability of cigarette smoking and general risk taking behaviors are relatively high. In the third class, the probability of general risk taking behavior, cigarette smoking, hookah smoking, and alcohol use is high. Finally, in the fourth class, the probability of all variables except sexual risk behavior is quite high among the participants. To the best of our knowledge, this study is the first attempt to use LCA for subgrouping of workers on the base of risk taking behaviors. There are some studies that have employed the LCA among specific groups in Iran like university students. ${ }^{19}$ Although researchers have used various indicator variables to indicate subgroups of risk taking 
behaviors among other population than workers, some of the relatively similar studies will be discussed below:

Deleuze et al found three separated subgroups of addictive behaviors in a community sample study, which were labeled as follow: Addition prone, mood regulators and non-addiction prone. ${ }^{29}$ Abbasi-Ghahramanloo et al were able to identify three latent classes for substance use pattern among university students in Tehran (capital of Iran), including non-users, users of low-stigma substances and drug users. ${ }^{30}$ In another study that was performed on university students in Bushehr (south of Iran) found five latent classes for risk taking behaviors among participants, including low risk, high risk, somewhat low risk, hookah user and very high risk. ${ }^{19}$

Considering the co-occurrence nature of risk taking behaviors is a very important approach in preventive interventions. Several studies have pointed out the co-occurrence of risk taking behaviors with each other. ${ }^{30,31}$ The findings of the present study indicated that $34.4 \%(27.8 \%$ in low risk class, $4.1 \%$ in moderate risk class and $2.5 \%$ in high risk class) of all workers engaged in risk taking behaviors with different patterns.

The results of the present study indicated that the prevalence of ADHD was $7.7 \%$ among workers. In Iran, there isn't a national estimation of adults ADHD, however, this disorder was assessed among some specific population. For example, among male prisoners, its prevalence reported as $16.2 \% .^{32}$ Also among university students, it was found that $15.4 \%$ of them had ADHD symptoms. ${ }^{33}$ In overall, it seems that the prevalence of ADHD is remarkably lower among workers than prisoners and university students. Research has consistently demonstrated that adults with ADHD would often have a broad range of problems such as substance abuse, more frequent changes in employment and multiple marriages, unemployment and career ability. ${ }^{15,34,35}$ Although the symptoms of ADHD along with its comorbid disorders (such as depression, phobias, and dysthymia) can increase the risk of engaging in risk taking behaviors, these are not the only determinants of risk taking behaviors. ${ }^{36}$ As a result, based on different situation and related factors, the pattern of risk taking behavior among a specific group like workers can differ from other population like university students. Among workers, individuals with ADHD may stop working due to this disorder and may have health insurance problems as they considered as high risk group. ${ }^{37}$ A representative study in ten countries showed that ADHD is associated with 22.1 annual days of excess loss of role performance compared to individuals without this disorder. ${ }^{38}$ A review by Frodl indicated that ADHD has high comorbidity with substance use disorders. The author concluded that adequate treatment of ADHD could reduce craving and relapse into substance use. ${ }^{39}$ Also, Lee et al in a review study reported that ADHD is a strong predictor of substance abuse regardless of participant's demographic characteristics. ${ }^{40}$ The findings of the present study reported that after adjusting for demographic and other related factors, ADHD increases the odds of membership in moderate risk class and high risk class significantly among workers. This is an important finding, and policymakers should carefully consider this in designing interventional programs in order to prevent or reduce risk taking behaviors among workers. As a result, treatment of ADHD can be quite effective in improving workers functioning in the workplace. Nevertheless, only a small percentage of workers with ADHD are treated in most countries. $^{38}$

Having unsafe sex or sexual risk behavior such as sex with multiple partners with inconsistent or non-use of condoms, exacerbate the spread of sexually transmitted infections. Only a few studies reported the prevalence of sexual risk behavior among workers. ${ }^{31}$ The present study showed that $3.2 \%$ of the workers reported sexual risk behaviors in the last year. This rate is quite low in comparison with a similar study among workers. ${ }^{31}$ Lower rate of sexual risk behavior in this study could be related to the difference in demographic characteristics of workers (like as age and marital status), cultural stigma against sexual risk behavior, disapproval of sexual risk behavior by families and probably fear of dismissal from work. Results from the present study also indicate that in the four class subgrouping of the workers, the sexual risk behaviors didn't play any role. This means that sexual risk behavior didn't co-occur with other risk taking behaviors. In previous similar studies on Iranian university students, sexual risk behavior showed more co-occurrence with other risk taking behaviors in LCA. ${ }^{3,19}$ As a result, we can say that among workers there are some individuals that engaged only in sexual risk behavior without doing other risk taking behaviors.

\section{Conclusion}

In this study, we reported the prevalence and pattern of risk taking behaviors among workers. We also evaluated the role of ADHD on the odds of membership in different latent classes identified by LCA. Results of this study 
showed that the majority of workers fell under the latent class of very low risk. In addition, it should be noted that although a small percentage of the workers are in high risk class, the probability of all items except sexual risk behavior is quite high in this class. We found that ADHD increases the odds of membership in moderate and high risk classes compared to latent class 1. Consequently, focusing on the treatment of ADHD with considering other comorbid factors such as anxiety may be helpful in designing and executing effective programs to reduce risk taking behaviors. Also some educational workshops in the workplace about risk taking behaviors could be effective in enhancing workers knowledge toward these behaviors.

\section{Abbreviations}

LCA, latent class analysis; AIC, Akaike Information Criterion; BIC, Bayesian Information Criterion.

\section{Acknowledgment}

This research was supported by grant No 96-03-27-31802 from Iran University of Medical Sciences. Also, we would like to thank Mr. Karim Shahidi and Mr. Hadi Azani for their assistance in data collection. We are also thankful to Dr. Hamid Reza Baradaran who shared his great experience.

\section{Author contributions}

All authors contributed to data analysis, drafting or revising the article, gave final approval of the version to be published, and agree to be accountable for all aspects of the work.

\section{Disclosure}

The authors report no conflicts of interest in this work.

\section{References}

1. Ansari-Moghaddam A, Ansari H, Mohammadi M, Khosravi S, SaneiMoghaddam E, Miri-Bonjar M. Predictors of high-risk behaviors in municipal workers and staff in Zahedan, South-East of Iran. Int J High Risk Behav Addict. 2016;5:4. doi:10.5812/ijhrba

2. Fuertes JN, Grindell SR, Kestenbaum M, Gorman B. Sex, parent attachment, emotional adjustment, and risk-taking behaviors. Int $J$ High Risk Behav Addict. 2017;6(2):1-12.

3. Mohammadpoorasl A, Ghahramanloo AA, Allahverdipour H. Risktaking behaviors and subgrouping of college students: a latent class analysis. Am J Mens Health. 2013;7(6):475-481. doi:10.1177/ 1557988313483540

4. Silva DA, Peres KG, Boing AF, González-Chica DA, Peres MA. Clustering of risk behaviors for chronic noncommunicable diseases: a population-based study in southern Brazil. Prev Med. 2013;56 (1):20-24. doi:10.1016/j.ypmed.2012.10.022
5. Poortinga W. The prevalence and clustering of four major lifestyle risk factors in an english adult population. Prev Med. 2007;44 (2):124-128. doi:10.1016/j.ypmed.2006.10.006

6. Coups EJ, Gaba A, Orleans CT. Physician screening for multiple behavioral health risk factors. Am J Prev Med. 2004;27(2):34-41. doi:10.1016/j.amepre.2004.04.021

7. Spicer RS, Miller TR. The evaluation of a workplace program to prevent substance abuse: challenges and findings. J Prim Prev. 2016;37(4):329-343. doi:10.1007/s10935-016-0434-7

8. Pidd K, Kostadinov V, Roche A. Do workplace policies work? An examination of the relationship between alcohol and other drug policies and workers' substance use. Int J Drug Policy. 2016;28:4854. doi:10.1016/j.drugpo.2015.08.017

9. Frone MR. Prevalence and distribution of illicit drug use in the workforce and in the workplace: findings and implications from a US national survey. J Appl Psychol. 2006;91(4):856. doi:10.1037/ 0021-9010.91.4.856

10. Shoham R, Sonuga-Barke EJ, Aloni H, Yaniv I, Pollak Y. ADHDassociated risk taking is linked to exaggerated views of the benefits of positive outcomes. Sci Rep. 2016;6:34833. doi:10.1038/srep34833

11. Pollak Y, Shalit R, Aran A. Risk taking and adult attention deficit/ hyperactivity disorder: a gap between real life behavior and experimental decision making. Psychiatry Res. 2018;259:56-62. doi:10.1016/j.psychres.2017.10.012

12. Schubiner H. Substance abuse in patients with attention-deficit hyperactivity disorder. CNS Drugs. 2005;19(8):643-655. doi:10.2165/ 00023210-200519080-00001

13. Edbom T, Granlund M, Lichtenstein P, Larsson J-O. ADHD symptoms related to profiles of self-esteem in a longitudinal study of twins a person-oriented approach. J Child Adolesc Psychiatr Nurs. 2008;21 (4):228-237. doi:10.1111/j.1744-6171.2008.00157.x

14. Schatz DB, Rostain AL. ADHD with comorbid anxiety: a review of the current literature. $J$ Atten Disord. 2006;10(2):141-149. doi: $10.1177 / 1087054706286698$

15. Kessler RC, Adler L, Barkley R, et al. The prevalence and correlates of adult ADHD in the United States: results from the national comorbidity survey replication. Am J Psychiatry. 2006;163(4):716723. doi:10.1176/ajp.2006.163.4.716

16. Abbasi-Ghahramanloo A, Heshmat R, Safiri S, et al. Risk-taking behaviors in iranian children and adolescents: a latent class analysis approach: caspian IV study. J Res Health Sci. 2018;18(4):e00428.

17. McAloney K, Graham H, Law C, Platt L. A scoping review of statistical approaches to the analysis of multiple health-related behaviours. Prev Med. 2013;56(6):365-371. doi:10.1016/j.ypmed.2013. 03.002

18. Meader N, King K, Moe-Byrne T, et al. A systematic review on the clustering and co-occurrence of multiple risk behaviours. $B M C$ Public Health. 2016;16(1):657. doi:10.1186/s12889-016-3373-6

19. Afrashteh S, Ghaem H, Abbasi-Ghahramanloo A, Tabatabaee HR. Clustering and combining pattern of high-risk behaviors among iranian university students: a latent class analysis. J Res Health Sci. 2017;17(4):e00398.

20. Amin-Esmaeili M, Rahimi-Movaghar A, Yunesian M, SahimiIzadian E, Moinolghorabaei M. Trend of smoking among students of Tehran university of medical sciences: results from four consecutive surveys from 2006 to 2009. Med J Islam Repub Iran. 2013;27 (4): 168.

21. Sadeghi-Bazargani H, Abedi L, Mahini M, Amiri S, KhorasaniZavareh D. Adult attention-deficit hyperactivity disorder, risky behaviors, and motorcycle injuries: a case-control study. Neuropsychiatr Dis Treat. 2015;11:2049. doi:10.2147/NDT

22. Anbarlouei M, Sarbakhsh P, Dadashzadeh H, et al. Cigarette and hookah smoking and their relationship with self-esteem and communication skills among high school students. Health Promotion Perspect. 2018;8(3):230-236. doi:10.15171/hpp.2018.31 
23. García JA, y Olmos FC, Matheu ML, Carreño TP. Self esteem levels vs global scores on the rosenberg self-esteem scale. Heliyon. 2019;5 (3):e01378. doi:10.1016/j.heliyon.2019.e01378

24. Kaviani H, Mousavi AS. Psychometric properties of the Persian version of Beck Anxiety Inventory (BAI). Tehran Univ Med J. 2008;66(2):136-140.

25. Lanza ST, Collins LM, Lemmon DR, Schafer JL. PROC LCA: a SAS procedure for latent class analysis. Struct Equ Modeling. 2007;14 (4):671-694.

26. Lanza ST, Bray BC. Transitions in drug use among high-risk women: an application of latent class and latent transition analysis. Adv Appl Stat Sci. 2010;3(2):203.

27. Nemati S, Rafei A, Freedman ND, Fotouhi A, Asgary F, Zendehdel K. Cigarette and water-pipe use in Iran: geographical distribution and time trends among the adult population; a pooled analysis of national STEPS surveys, 2006-2009. Arch Iran Med. 2017;20(5):295.

28. Meysamie A, Ghalehtaki R, Ghodsi S, et al. Trend of cigarette smoking in Iranian adult population from 2000 to 2011 based on four national surveys. Social Determinants Health. 2017;3(3):148-159.

29. Deleuze J, Rochat L, Romo L, et al. Prevalence and characteristics of addictive behaviors in a community sample: a latent class analysis. Addict Behav Rep. 2015;1:49-56. doi:10.1016/j.abrep.2015.04.001

30. Abbasi-Ghahramanloo A, Rahimi-Movaghar A, Zeraati H, Fotouhi A. Pattern of substance use among students of medical sciences in Tehran, Iran: a latent class analysis. J Subst Use. 2018;23(6):648654. doi:10.1080/14659891.2018.1489007

31. Al Rifai R, Nakamura K, Seino K, Kizuki M, Morita A. Unsafe sexual behaviour in domestic and foreign migrant male workers in multinational workplaces in Jordan: occupational-based and behavioural assessment survey. BMJ Open. 2015;5(6):e007703. doi:10.1136/bmjopen-2015-007703

32. Hamzeloo M, Mashhadi A, Salehi Fadardi J. The prevalence of ADHD and comorbid disorders in Iranian adult male prison inmates. J Atten Disord. 2016;20(7):590-598. doi:10.1177/1087054712457991
33. Mosalanejad M, Mosalanejad L, Lashkarpour K. Prevalence of ADHD among students of Zahedan university of medical science in Iran. Iran J Psychiatry Behav Sci. 2013;7(2):83.

34. Faraone SV, Wilens TE, Petty C, Antshel K, Spencer T, Biederman J. Substance use among ADHD adults: implications of late onset and subthreshold diagnoses. Am J Addict. 2007;16(Suppl 1):24-32. quiz 3-4. doi:10.1080/10550490601082767

35. Kessler RC, Adler L, Ames M, et al. The prevalence and effects of adult attention deficit/hyperactivity disorder on work performance in a nationally representative sample of workers. J Occup Environ Med. 2005;47(6):565-572.

36. Bakhshani N-M. Attention-deficit/hyperactivity disorder (ADHD) and high risk behaviors. Int J High Risk Behav Addict. 2013;2(1):1. doi:10.5812/ijhrba. 12817

37. Ginsberg Y, Quintero J, Anand E, Casillas M, Upadhyaya HP. Underdiagnosis of attention-deficit/hyperactivity disorder in adult patients: a review of the literature. Prim Care Companion CNS Disord. 2014;16(3):1-8.

38. de Graaf R, Kessler RC, Fayyad J, et al. The prevalence and effects of adult attention-deficit/hyperactivity disorder (ADHD) on the performance of workers: results from the WHO world mental health survey initiative. Occup Environ Med. 2008;65(12):835-842. doi:10.1136/oem.2007.038448

39. Frodl T. Comorbidity of ADHD and Substance Use Disorder (SUD): a neuroimaging perspective. J Atten Disord. 2010;14(2):109-120. doi: $10.1177 / 1087054710365054$

40. Lee SS, Humphreys KL, Flory K, Liu R, Glass K. Prospective association of childhood attention-deficit/hyperactivity disorder (ADHD) and substance use and abuse/dependence: a meta-analytic review. Clin Psychol Rev. 2011;31(3):328-341. doi:10.1016/j.cpr. 2011.01.006
Neuropsychiatric Disease and Treatment

\section{Publish your work in this journal}

Neuropsychiatric Disease and Treatment is an international, peerreviewed journal of clinical therapeutics and pharmacology focusing on concise rapid reporting of clinical or pre-clinical studies on a range of neuropsychiatric and neurological disorders. This journal is indexed on PubMed Central, the 'PsycINFO' database and CAS, and

\section{Dovepress}

is the official journal of The International Neuropsychiatric Association (INA). The manuscript management system is completely online and includes a very quick and fair peer-review system which is all easy to use. Visit http://www.dovepress.com/testimonials.php to read real quotes from published authors. 